\title{
On the concordance of 21st Century wind-wave climate projections
}

Joao Morima ${ }^{\mathrm{*}}$, Mark Hemerb, Nick Cartwrighta1, Darrell Strauss ${ }^{\mathrm{a} 2}$, Fernando Andutta ${ }^{\mathrm{a} 3}$

aGriffith University, Gold Coast, Southport, Queensland 4222, Australia, Ph: (+61) 755528572

bThe Commonwealth Scientific and Industrial Research Organisation (CSIRO),

Hobart, Tasmania 7001, Australia, Ph: (+61) 362325017

E-mail: mark.hemer@csiro.au

E-mail11: n.cartwright@griffith.edu.au

E-mail2: d.strauss@griffith.edu.au

E-mail3: f.andutta@griffith.edu.au

${ }^{*}$ Corresponding author, E-mail: joao.morimnascimento@griffithuni.edu.au 


\section{Abstract}

Understanding anticipated climate-induced changes in the global wind-wave climate is paramount for sustainable development of coastal and ocean industry-operations, resources, ecosystems and for the mitigation of potential impacts on coastal settlements. Intensive research has been placed into global and regional wave climate projections over the past 10 years, but no systematic review has been conducted to date. Here, we present a consensus-based analysis of 91 published global and regional scale wind-wave climate projection studies to establish consistent patterns of impacts of global warming on the wind-wave climate across the globe. Furthermore, we critically discuss research efforts, current limitations and identify opportunities within the existing community ensemble of projections to resolve various sources of uncertainty amongst the sparsely sampled set of future scenarios. We find consensus amongst studies regarding an increase of the mean significant wave height $\bar{H}_{\mathrm{s}}$ across the Southern Ocean, tropical eastern Pacific and Baltic Sea, and conversely, a decrease of $\bar{H}_{\mathrm{s}}$ over the North Atlantic and Mediterranean Sea. Furthermore, we observe that projections of $\bar{H}_{\mathrm{s}}$ over the eastern north Pacific and southern Indian and Atlantic Oceans lack consensus. Similarly, future projections of extreme $H_{\mathrm{s}}$ lack consensus everywhere, except for the Southern Ocean and North Atlantic. We note a distinct lack of research regarding projected changes in wave direction which is of critical importance particularly for the mitigation of coas tal hazards. Furthermore, we observe that the projection uncertainty surrounding wind-wave climate projections has been poorly sampled. Subsequently, we identify sets of coordinated experiments within existing studies that can be used as a basis to systematically quantify these uncertainties. Lastly, we recommend a shift towards a systematic, community-based framework (as propose by the COWCLIP) to foster concerted efforts and to better inform the wide range of relevant decisions across ocean and coastal adaption and mitigation assessments. 


\section{Introduction}

Wind generated ocean waves are considered one of the eight main climate drivers affecting the coastal environment and are key contributors to shoreline erosion, storm surge and flooding (Ranasinghe, 2016; Sierra and Casas-Prat, 2014). Whilst there is evidence that the influence of a changing wind-wave climate might further exacerbate or even dominate relative to the influence of sea-level rise across some coastal regions (Coelho et al., 2009), the combined influence of these non-stationary processes will likely have a significant impact on coastal nearshore zones. Despite being a key component of the Earth's climate system (Young et al., 2011), and increasing awareness of sea-state as an essential climate variable, windwave parameters are not yet available as an output from Atmosphere-Ocean General Circulation Models (AOGCMs) which are widely used to characterize the climate system (Nicholls et al., 2007). Consequently, and as noted in the Fifth Assessment Reports (AR5) of the Intergovernmental Panel on Climate Change (IPCC) (Field et al., 2014), knowledge of projected changes in the wind-wave climate is limited relative to other climate variables such as temperature and precipitation; as particularly noted in the Fifth Assessment Reports (AR5) of the Intergovernmental Panel on Climate Change (IPCC) (Field et al., 2014). Having recognized that the wind-wave climate responds to climate variability and change, and that there are broad socio-economic and environmental consequences of such changes (Hoeke et al., 2013), a growing number of studies have been completed by the international scientific research community to understand how the global- and regional- wave climate systems may potentially respond to different trajectories of increasing greenhouse gas emissions forcing over the $21^{\text {st }}$ century (Fig. 1). While scientific efforts are underway to coordinate the next generation of wave-climate projection studies, a lack of coordination and integrated consensus exists within the existing 'ensemble' of published studies (Hemer et al., 2013a) the IPCC AR5 constrained to state that projected changes are qualitatively uncertain (Church et al., 2013, Field et al. 2014). 


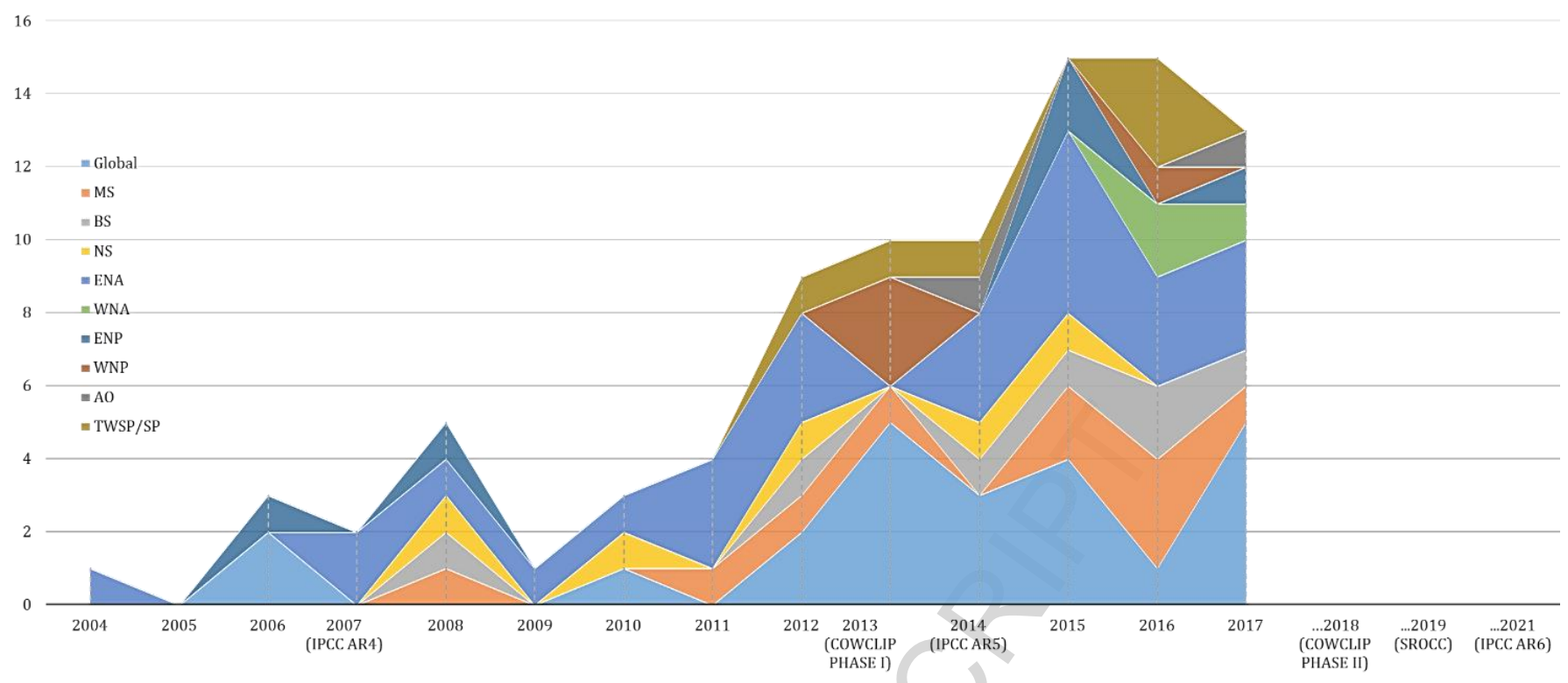

Fig. 1. Number of global and regional-scale studies per year projecting change in wind-wave climate completed since 2004. Also indicated on the x-axis are the years of release of IPCC Assessment Reports (IPCC AR5 and AR6), IPCC Special Report on the Ocean and Cryosphere in a Changing Climate (SROCC) and the COWCLIP Phase I and II inter-comparison analysis. The acronym of each region has been defined in the Supplementary Information and in Fig. 3. The list of existing studies considered for analysis is given in the Supplementary List S1 with details summarized in Supplementary Table S1 and S2.

Due to a number of factors including limited study scope, computational resources and/or availability of suitable climatological data sets, different climate modelling groups have adopted conceptually different methods of deriving wave-climate projections, and have considered different forcing conditions obtained from a select few emission scenarios, using a select few AOGCM simulations. As a result, projection uncertainty has been treated very differently leading to contrasting lines of evidence in the literature. Individual studies have therefore been systematically limited within the full uncertainty sample space and consequently are unable to quantify the uncertainty inherent to the projection modelling process (Fig. 2). Distinguishing the anthropogenically-forced climate changes from the variance induced by the different sources of uncertainty (and from the natural background variability) is needed to reliably incorporate wave climate projections into coastal adaptation and mitigation decision making. Moreover, inconsistencies in modelled historical and future time-slices and projected wave climate variables exist. These aspects combined have systematically hampered our ability to move forward with consensus and need consolidation to support defining the way forward. These has been recognized by the Coordinated Ocean Wave Climate Project (henceforth COWCLIP) (Hemer and Wang, 2017; Hemer et al., 2010; Hemer et al., 2012), a coordinated international scientific collaboration which seeks to support assessments of historical and projected future wave climate variability and change.

In this context, we provide the first systematic, consensus-based analysis which consolidates multiple independent lines of evidence from 91 published global and regional-scale wave-climate projection studies. Furthermore, we critically discuss the research effort to address projection uncertainty and analyse the sample overlap amongst existing studies to identify opportunities to isolate/resolve these 
uncertainties using existing data sets. The analysis presented provides support to the COWCLIP Phase 2 inter comparison study and represents a critical step in evaluating the robustness of future projections of wind-wave climate change at both regional- and global-scales.

The article is divided into four sections. In section 2, we describe the wave-climate projection process, modelling frameworks, and corresponding sources of projection uncertainty. In section 3 we present the findings of the systematic, consensus-based review of projected changes in the global and regional wave climate. In section 4, we discuss the sample space coverage (uncertainty, parameter, temporal and spatial spaces) in the existing ensemble of wave climate projections. In section 5, we identify opportunities within the existing studies to isolate and resolve the subsets of the uncertainty space. In section 6 , we present key conclusions.

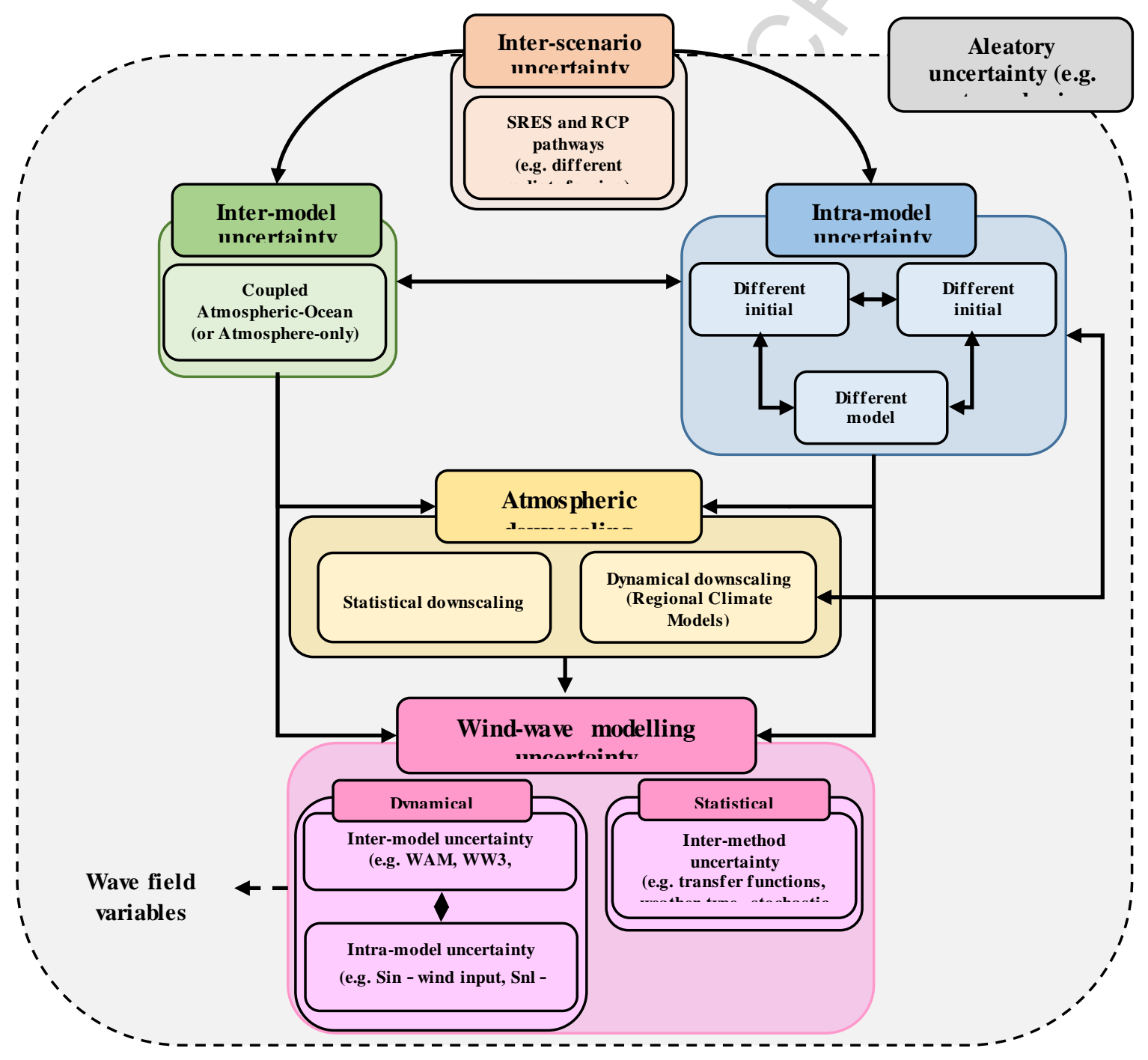

Fig. 2. Schematic representation of the cascading sources of uncertainty (and the different modelling frameworks) associated with the various stages of the wave-climate projection process (the definition of each source of uncertainty is given in the Supplementary Information). Each subset of the uncertainty 
space is assigned a different colour code, with the black arrows representing the interaction between the different subsets and illustrating the growth of the envelope of uncertainty.

\section{Approach}

\subsection{Data sources}

Information was collected from 91 publicly available wave climate projection studies published in the peer-reviewed, and grey literature at the time of writing (see Supplementary List S1). The wind-wave climate projection studies reviewed in this synthesis are summarised in supplementary Table S1 which includes information on (1) publication citation; (2) study area; (3) climate forcing scenarios analysed; (4) AOGCM used for future projection; (5) atmospheric downscaling approach, i.e. number and name of atmospheric/regional model or statistical methods used; (7) wind-wave modelling approach, i.e. name of spectral wave models/source terms and/or statistical methods applied; (8) spatial resolution of projections provided; (9) projection time-slices; (10) research institution. In addition, supplementary Table S2 summarises information on archived, validated and projected wave variables/statistics and data sets, time periods and skill metrics of performance used for verification of wave simulations. To facilitate the comparison of findings between global and regional-scale wind-wave projections and account for regional variability, studies have been organized in temporal space (Fig. S1) across 21 sub-regions of the global ocean defined on the basis that wind-wave climate characteristics in each particular domain are qualitatively similar (Alves, 2006; Hemer and Trenham, 2016). A study was allocated to a given region when it explicitly examined the projected change in wind-wave parameter(s) within that region.

\subsection{Evaluation of inter study consensus}

\subsubsection{Time slice and wave parameters}

The end of $21^{\text {st }}$ century period (2070-2100) was used for analysis, as the largest temporal overlap is available within this period amongst the existing studies (see Fig. S1). We noted differences in the definition of the present and future wave climates (time-span and time periods) amongst the studies (Fig. S1). To enable the intercomparison, it is assumed that any such differences are attributable to model error and are not from the variability of the wind-wave climate and hence choice of time slice (Hemer et al., 2013a).

We limited our qualitative intercomparison to the mean and extreme $H_{\mathrm{s}}$ since this is the only wind-wave variables with sufficient overlap between existing studies to allow an informed analysis and integration of the results. Section 3 provides a detailed discussion on the scarcity of studies examining projected changes in wave period and/or direction. To enable a larger overlap in the wave-parameter space associated with future changes in extreme storm-wave events, projected changes in return periods (more than 20 years), annual mean maximum values and 95/99th percentiles were considered together.

Whenever duplicated results were encountered, only the most explicit result available was retained (see Supplementary Information).

\subsubsection{Consensus analysis}


The consensus-based analysis of the climate change signal was based on the IPCC AR5 guidelines (Mastrandrea et al., 2010; Mastrandrea et al., 2011), in which the direction of change as a response to global warming is qualitatively appraised based on (1) the amount of available evidence and (2) the level of consensus (the level of concurrence in the literature on the signal of change) (Stanton et al., 2016). No weighting, or ranking, of any study over another was applied, since the provision of wind-wave climate projections is still in its infancy, and standard metrics for study quality are yet to be defined (Hemer et al., 2013a; Hemer and Trenham, 2016).

For each article reviewed, the signal of change in both the mean and extreme $H_{s}$ was ascribed as either positive $(+)$, negative $(-)$, or no change $(0)$. For $\bar{H}_{s}$, the climate change signal map was generated by normalizing the sum of the signals appraised by the various studies, as the multi-model or multi-run ensemble mean difference between present and future wind-wave climates. The reasoning behind this is that the skill of an ensemble outperforms the skill of its members (Hemer and Trenham, 2016) because it filters out biases of individual GCMs, apart from pervasive errors. When the ensemble mean was not available, a sign was attributed solely when all ensemble members agreed in the signal of change. For the extreme $H_{\mathrm{s}}$, the climate change signal map was derived by normalizing the sum of signals assessed by the different studies as the individual results from all the ensemble members when available; otherwise the ensemble extreme was used.

We acknowledge the following limitations to the adopted approach used is inherently subject to as the following: the element of subjectivity that is introduced whenever multiple sub-areas within a region exhibits contrasting trends in the climate change signal; or when there is agreement at spatial scales smaller than the domains considered. In the first case, we avoided attributing a signal of change when results are not consistent and explicit regarding the direction of projected change (positive, negative or no change) and used a symbol \pm to denote regions where the direction of change is inconclusive (spatially varying) at the scale of our domains.

\subsubsection{Isolation of projection uncertainty amongst the community ensemble}

There is a large number of forcing AOGCM models used within published studies (Supplementary Table 1). To support multiple coordinated experiments we grouped CMIP3 and CMIP5 GCMs into 4 different statistically analysed clusters each having a different annual-average tropical SST (sea surface temperature) spatial anomaly pattern (Mizuta et al., 2014; Murakami et al., 2011). The reasoning behind this is that common features in the projected change signal in the mean/extreme wave climate are attributable to the SST characteristics of the forcing AOGCM models (Bennett et al., 2016; Mizuta et al., 2014; Murakami et al., 2012; Shimura et al., 2015a; Shimura et al., 2015b). Since multiple studies have used surface wind field outputs from the EC-EARTH AOGCM, we grouped these datasets under cluster ECEARTH. We assume that all experiments and datasets within the community ensemble were obtainable for each computational grid described. When no information on the AOGCM initial conditions was reported, the simulations were assumed to be the standard unperturbed run. The spatial extent of each dataset has also been taken into account. The results of this comparison can be found in section 3.5.

\section{Results}




\subsection{Scientific consensus amongst wind-wave climate projections}

Fig. 3a shows the projected changes in annual and seasonal mean significant wave height $\left(\bar{H}_{\mathrm{s}}\right)$ for the end of the $21^{\text {st }}$ century period (2070-2100) for different climate forcing scenarios across 21 subregions of the global oceans. An agreed increase in $\bar{H}_{\mathrm{s}}$ is projected in the Southern Ocean and tropical eastern Pacific Ocean across all seasons and projection scenarios, consistent with the intensification and poleward shift of the westerly winds (Sigmond et al., 2011), and also with the increasing Southern Ocean southerly swell contribution (Hemer et al., 2013a). In the tropical western south Pacific, an agreed increase is projected in annual and winter $\bar{H}_{\mathrm{s}}$. In the North Atlantic Ocean, Mediterranean Sea and western North Sea, a projected decrease in $\bar{H}_{\mathrm{s}}$ is found spanning all seasons and scenarios, generally consistent with projected wind changes in the CMIP3 A1B multi-model dataset (McInnes et al., 2011). In the Baltic Sea, a projected increase is observed across all seasons and scenarios. The eastern North Sea is a region of projected increase in $\bar{H}_{\mathrm{s}}$ under the SRES A1B scenario and of decrease under the RCP8.5 scenario, suggesting that $\bar{H}_{\mathrm{s}}$ in this region is more sensitive to the strength of the climate-forcing scenario.

In the western north Pacific a projected decrease in annual and winter $\bar{H}_{\mathrm{s}}$ is found under RCP4.5/RCP8.5 forcing scenarios. In the northern Indian and southern extra-tropic regions, an agreed decrease in annual and summer $\bar{H}_{\mathrm{s}}$ is projected based on the SRES A1B and RCP8.5 scenarios respectively, but no consensus is observed for any other forcing scenario and/or season. In the Arctic Sea, a projected increase in annual $\bar{H}_{\mathrm{s}}$ is expected owing to increasing fetch associated with retreating sea-ice coverage (Aarnes, 2017; CasasPrat et al., 2018; Khon, 2014), but is based on a limited number of projections. The predominant patterns of projected future change in $\bar{H}_{\mathrm{s}}$ in our analysis are generally consistent with the current understanding of future changes in the atmospheric circulation in response to anthropogenic global warming (Arblaster et al., 2011; Ma et al., 2016; McInnes et al., 2011).

In contrast, the projected change in $\bar{H}_{\mathrm{s}}$ lacks consensus across the remaining global ocean basins, most prominently in the northern eastern Pacific and southern Indian and Atlantic oceans. The observed lack of consensus over these regions can be attributed to the variable skill of AOGCM-forced wave simulations to represent the wind-wave field response associated with atmospheric climate mode variability depending on the region (Hemer and Trenham, 2016).

Limited studies provide information on extreme $H_{\mathrm{s}}$, where concurrence in projected change across all scenarios is limited to the Southern Ocean (agreed increase) and the eastern North Atlantic and Mediterranean Sea (agreed decrease) (Fig. 3b). The lack of agreement across many regions can be attributed to several factors: the forcing AOGCMs of many of the considered studies have insufficient spatial resolution to adequately resolve extreme storm events; extreme wave conditions vary with shorter length scales than the scale of our adopted ocean domains (Fig. 3) and therefore variability of extremes within subdomains will be present; a lack of standardization within the community in terms of statistics used to define extreme conditions (e.g. return periods vs percentiles) (Fig. 5). 

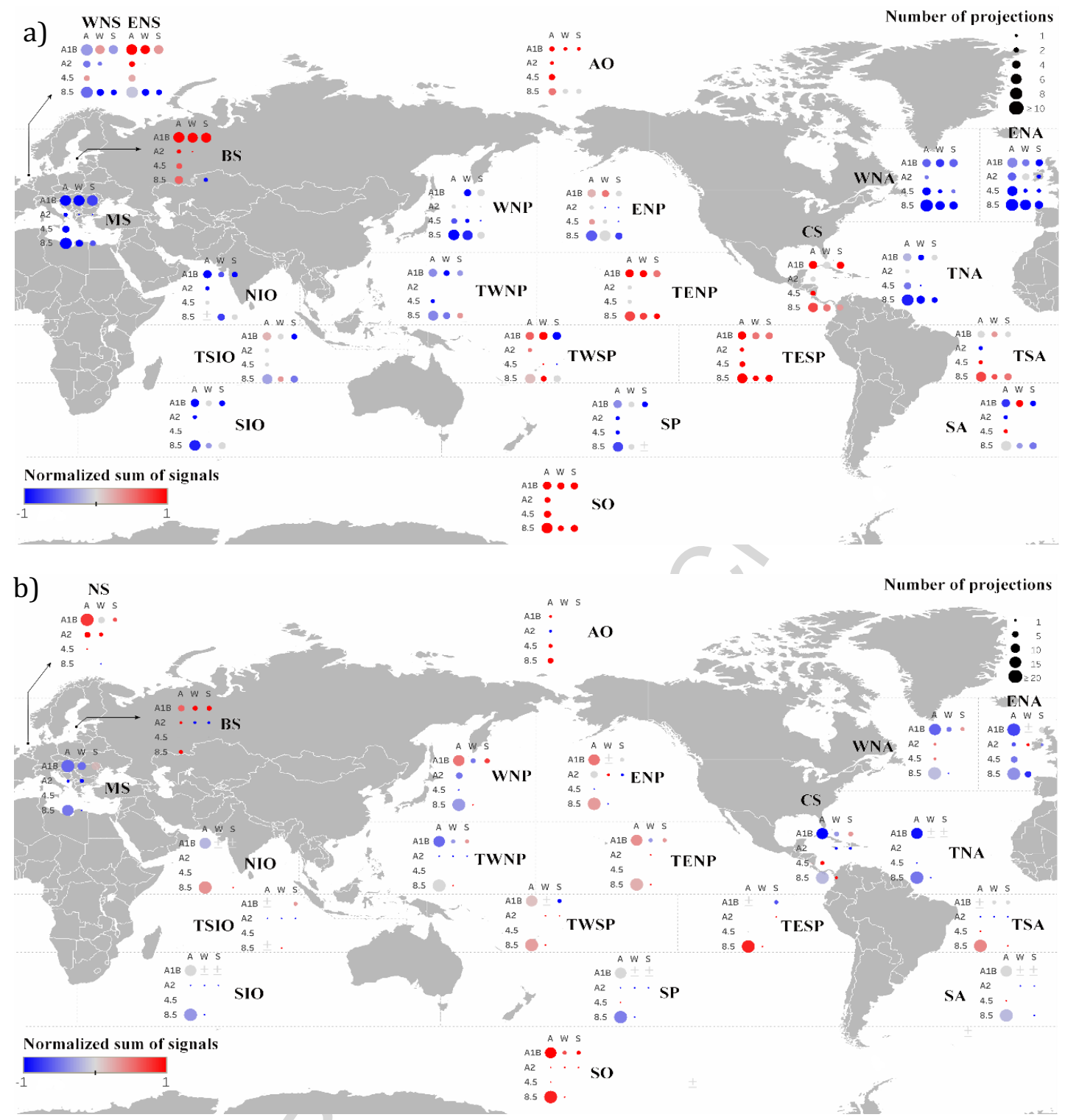

Fig. 3. Level of consensus in projected future changes in significant wave height. Signals of climate change in annual (A), winter (W) and summer (S) mean $H_{\mathrm{S}}(\mathrm{a})$ and extreme $H_{\mathrm{S}}(\mathrm{b})$ for the end of the 21st century $(\sim 2070$ to 2100$)$ relative to the present-climate period for alternative greenhouse-gas concentrations pathways (SRES A1B/A2 and RCP4.5/8.5) across the global ocean. The consensus in the direction of the projected change is expressed as the normalized sum of the signals as estimated by the different waveclimate studies (see colorbar and section 3) where dark blue indicates a projected decrease and dark red indicates a projected increase. The symbol \pm is assigned to regions with spatial variability at the subregion scale.

\subsection{Sample space analysis}

\subsubsection{Spatial distribution of regional projections}


Regional wind-wave climate projections generate valuable input to regional coastal impact and adaption assessments. These studies have used dynamically-downscaled data derived from Atmospheric-Ocean General Circulation Model (AGCM) and Regional Climate Models (RCM) nested within and driven by boundary conditions taken from coarser time-space AOGCM data. The higher spatial-scale resolution (ca. 10-50 km) enables AGCMs/RCMs to capture the details of orography and resolve important cyclonic disturbances that are not captured in AOGCMs (spatial resolution of ca. 100-400 km) (Flato et al., 2013). However, regional studies to date have mostly been conducted in developed regions such as the eastern North Atlantic and North, Baltic and Mediterranean Seas (Fig. 4). Consequently, many coastal regions at greater risk have been overlooked with wide gaps in the global coverage particularly in those areas where effects of climate change are likely to be more detrimental for coastal human settlements (see red line in Fig. 4). This is the case for southeast Asia, where countries like China, Indonesia, Bangladesh, Viet Nam and India have some of the largest populations living within the Low Coastal Elevation Zone (LCEZ) and the highest rate of population growth urbanisation (Neumann et al., 2015), but wind-wave climate projections are seen to be sparse (Fig. 4).

This indicates that further efforts should prioritize these areas where policies and adaptive planning for coastal human settlements are not only desirable but rather essential (Neumann et al., 2015). Other areas of the global ocean that should be likewise prioritized are the highly vulnerable low-lying tropical Pacific and Indian Islands where impacts of seal-level rise and wave-induced flooding are likely to be severe and adaptive capacity is reduced (Albert et al., 2016; Hoeke et al., 2013). Whilst the future effects of wave climate change will be highly variable in terms of the extent of projected change, the adaptive capacity of the coastal settlements (including industries) considered will also play a key role. 


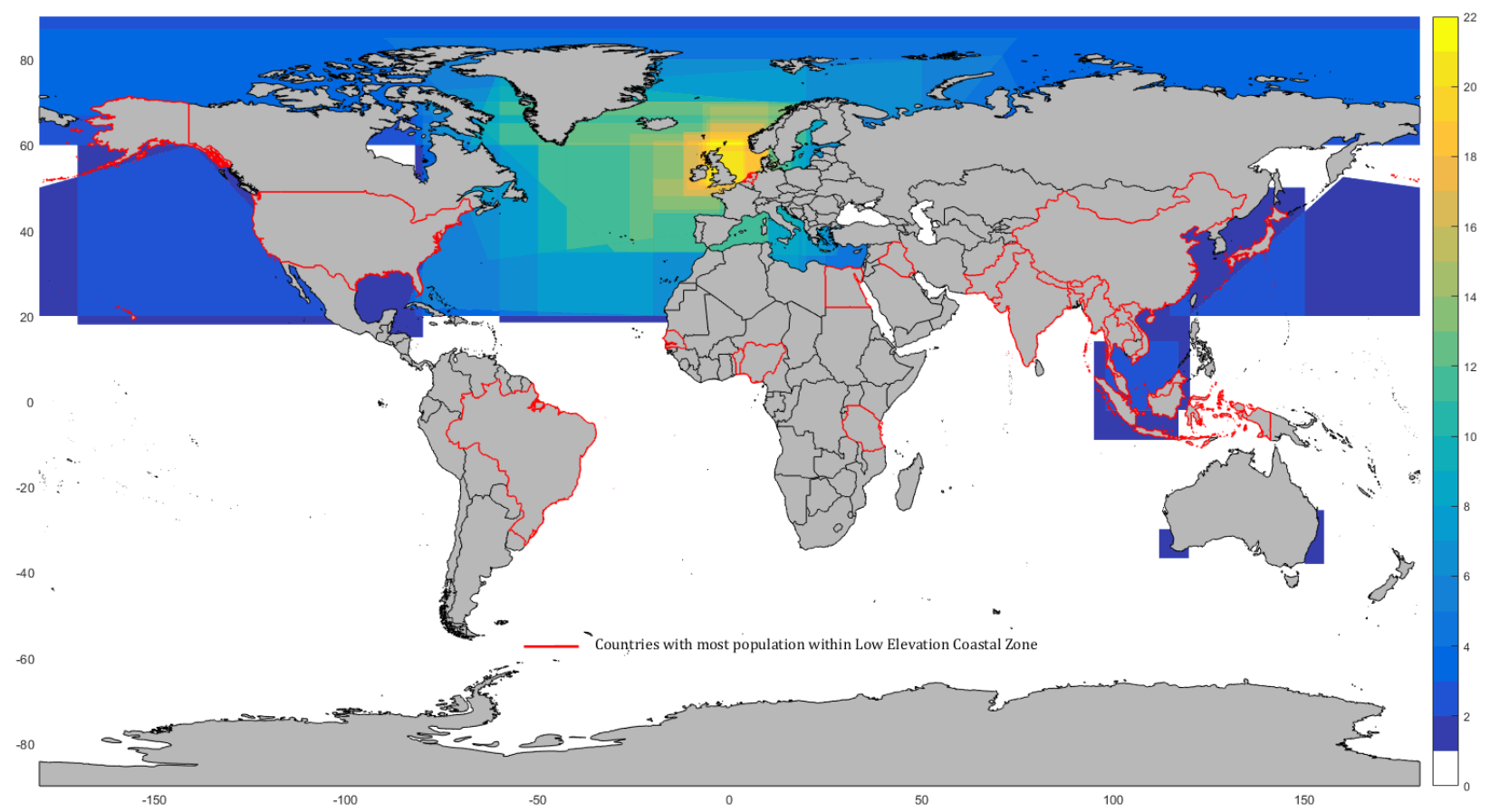

Fig. 4. Global distribution of regional-wave climate projection studies in terms of datasets coverage. The colour code expresses the number of spatially overlapping data sets within the community ensemble of wind-wave climate projections. The spatial extent of each dataset was considered as reported by each study. The red borderlines indicate the top 20 countries with highest projected population within the Low Elevation Coastal Zone (LECZ) in the year 2030 and 2060 (Neumann et al., 2015).

\subsection{Projection uncertainty space}

Fig. 6 shows the sampling of the different subsets of the uncertainty space at global and regional-scales, with each uncertainty previously defined in Fig. 2. These results show that community scientific efforts to sample across the different subsets of the uncertainty space has been systematically limited regardless of the ocean regions considered. The influence of uncertainty is currently greater than the extent of any projected changes (Hemer et al., 2013a). Study efforts have tended to concentrate on sampling intermodel and/or inter-scenario uncertainty and rarely consider intra-model variance stemming from the natural chaotic variability of the climate system. Similarly, little effort has been devoted towards systematically sampling atmospheric downscaling and/or modelling uncertainty despite the fact that many studies have relied on high-resolution AGCMs/RCMs to obtain enhanced representation of wavegenerating synoptic systems at regional scales (Supplementary Table S1). Such downscaling approaches introduces another level of variance which is difficult to quantify (Giorgi and Jr., 2015). The COWCLIP Phase-I global intercomparison analysis suggests that the uncertainty introduced through atmospheric wind downscaling and wave modelling dominates the variance observed within an ensemble of windwave climate simulations (Hemer et al., 2013a; Hemer and Trenham, 2016). The relative magnitude of these sources of uncertainty remains largely unquantified, with international research groups currently attributing the full observed spread between GCM-forced wave simulations solely to inter-model and/or inter-scenario differences. 
a)

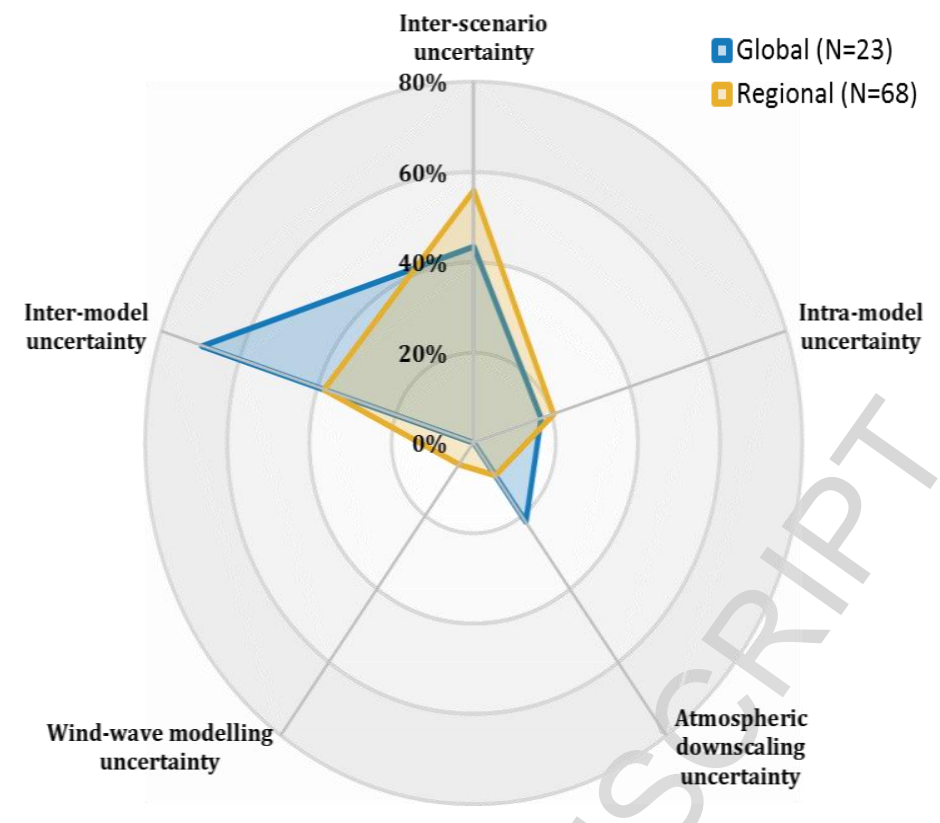

b)
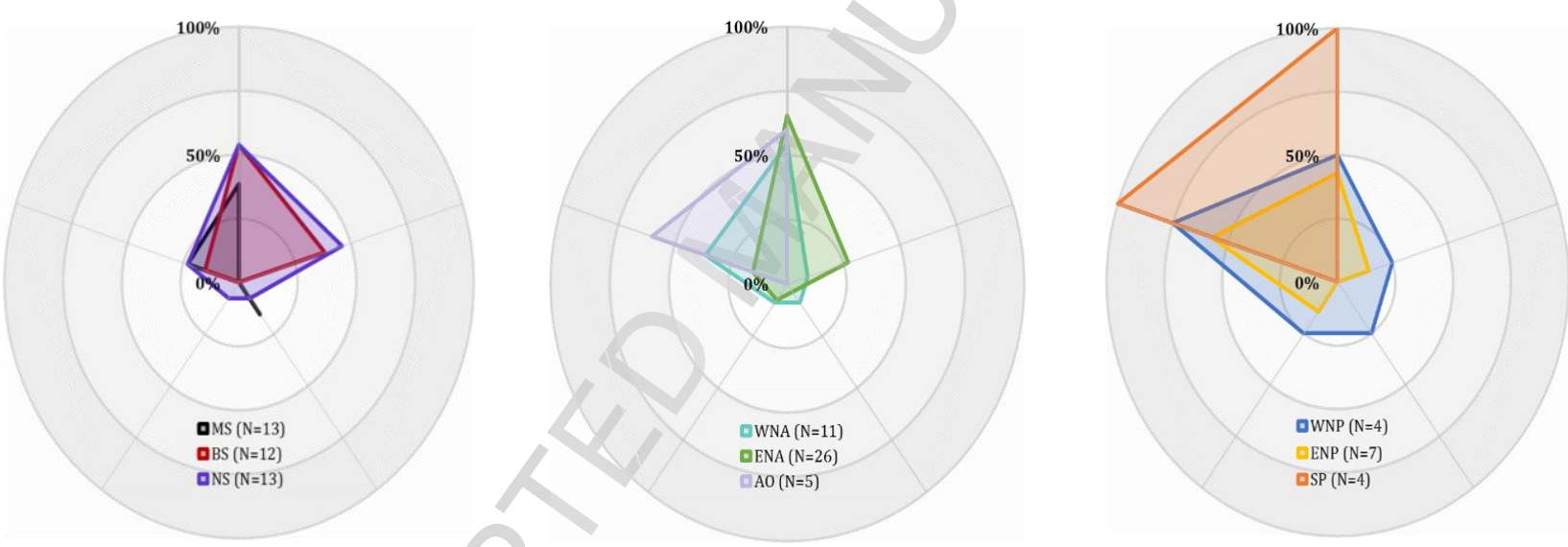

Fig. 5. Comparison of the relative modelling effort within the wave community in terms of sampling across the uncertainty space at the global (a) and regional-scales (b). Numbers are presented as the normalized percentage of studies that sampled each of the different sources of uncertainty intrinsic to the projection modelling process (see Fig. 3 for the schematic representation of cascading uncertainty). The blue colour code corresponds to global-scale projections and dark yellow code to regional-scale projections. The legends for each plot are the same with each specific colour code representing a specific region. The region acronyms have been geographically defined in Fig. 3. 


\subsection{Wave parameter space}

Fig. 6 shows the sampling of the wave parameter space at global and regional-scale. Given the wide range of statistics reported, results have been grouped into 9 different classes defined based on their similarity. Research efforts have primarily focused on projecting changes in annual $\bar{H}_{\mathrm{s}}$. At regional scales, modelling groups have considered potential changes in extreme $H_{\mathrm{s}}$ based on different extreme-value statistics to address concerns of local policy makers in developed regions, particularly North Europe. Furthermore, little regard has been given to future changes in temporal variability and/or other wave parameters such as wave period $(T)$ and direction $(\theta)$. Longshore sediment transport and hence shoreline stability is known to be particularly sensitive to directional wave changes over all time-scales (Goodwin et al., 2013; Harley et al., 2017; Ruggiero et al., 2010). The IPCC Working Group 2 (WG2) emphasizes that sediment-budget information is paramount for estimating coastal erosion and deposition (Field et al., 2014), hence knowledge on projected changes in wave direction is needed to satisfactorily inform adaption and mitigation strategies in ocean/coastal environments. Similarly, projected changes in wave direction are needed in other fields such as renewable wave energy (Morim et al., 2016), where non-axisymmetric wave conversion technologies have to be aligned towards the prevailing wave direction.

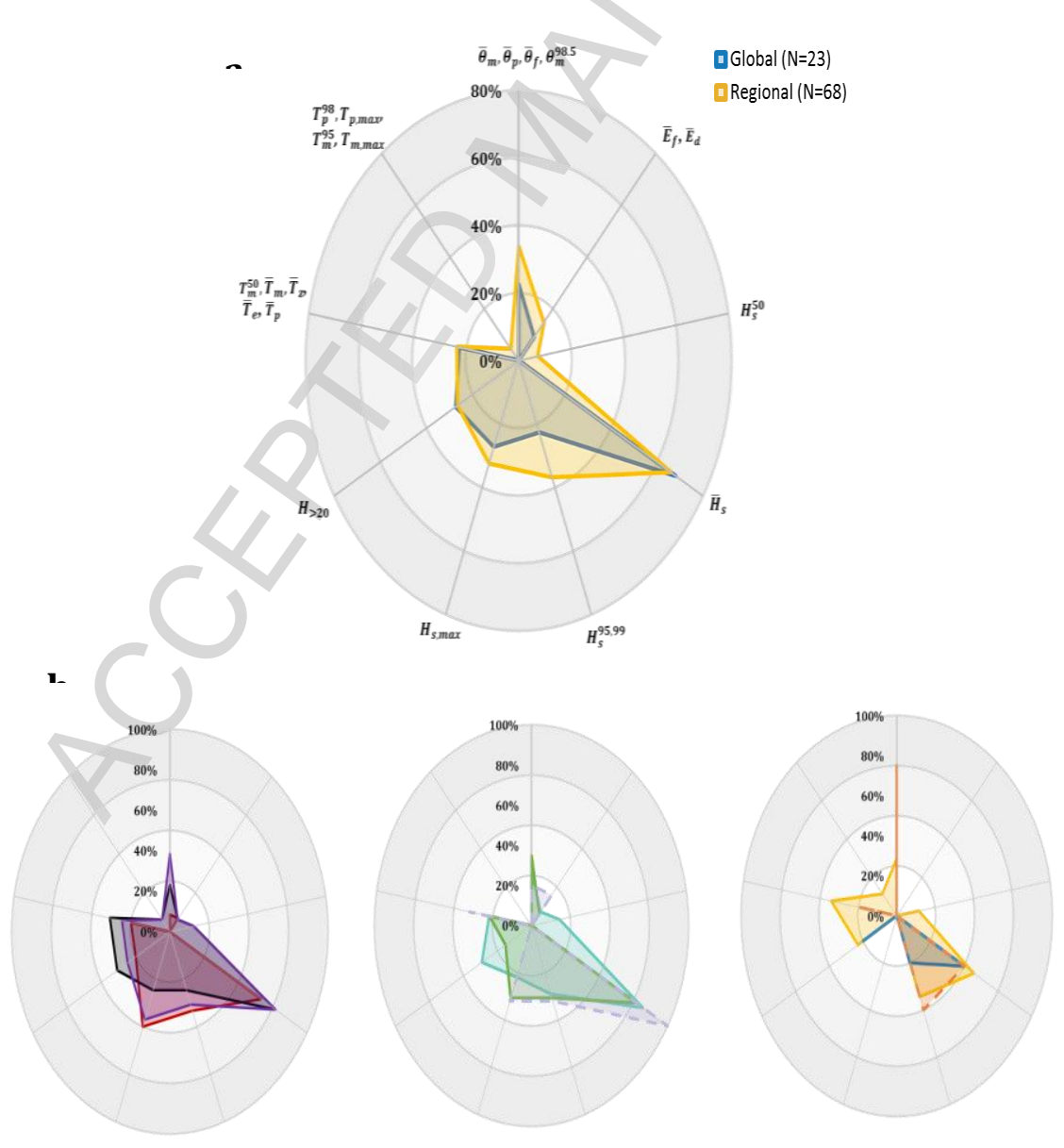

Fig. 6. Comparison of the relative modelling effort within the wave community in terms of sampling across the parameter space at the global (a) and regional-scales (b). Numbers are presented as the 
normalized percentage of studies that projected each of the different wave-climate variables and/or their divergent statistics. When a study provided projected changes for multiple statistics within the same category, we considered it as one entry and when duplicated results were encountered, we retained only the most explicit result (see Supplementary Information). The blue colour code corresponds to globalscale projections and dark yellow code to regional-scale projections. The legends for each plot are the same as in Fig. 5 in terms of colours with each specific colour code representing a specific region. The region acronyms have been geographically defined in Fig. 3.

\subsection{Temporal space}

Considerable inconsistencies in the time-slices considered to represent the historical and projected wave-climates exist (Fig. S1 and Fig. 7). The most targeted projection window for the future climate is the end of the $21^{\text {st }}$ century period (2080-2100), which corresponds to the period of availability of high spatial-temporal resolution surface wind field outputs from the CMIP5 experiments (Taylor et al., 2012) (Fig. 7). In terms of time-span, the length of time-slices used within the community (typically around 20years) insufficiently accounts for inter-decadal variability and hence it is currently difficult to distinguish between the magnitude of projected wave-climate change and the long-term, background variability.
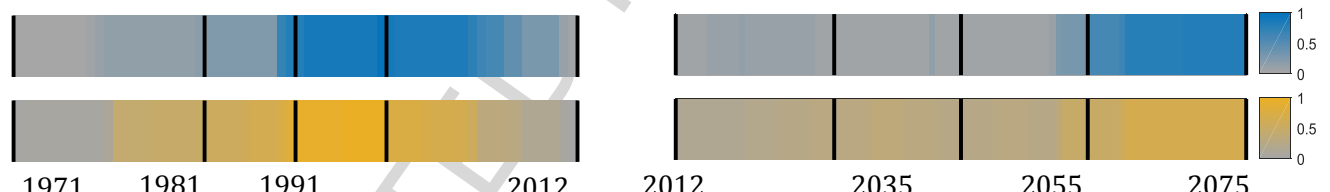

Fig. 7. Comparison of the relative modelling effort within the wave community in terms of sampling across the temporal space at the global (a) and regional-scales (b). On the left hand side of each pair, we show the overlap in temporal space in terms of historical (1950-2012) time-slices amongst the different studies. On the right hand side of each pair, we show the overlap in temporal space in terms of future (2012-2100) time-slices amongst the different studies. The scale is normalized by the number of studies. The blue colour code corresponds to global-scale projections and dark yellow code to regional-scale projections. The legends for each plot are the same as in Fig. 5 in terms of colours, with each specific colour code representing a specific region. The region acronyms have been geographically defined in Fig. 3.

\subsection{Analysis of systematic uncertainty}

\subsubsection{Model validation}


Projected changes to the wave climate should be viewed in the context of the adopted models ability to reproduce the observed historical wave climate. To understand how well climate-model derived wave fields represent the climatological mean state and temporal variability of the historical wave climate, results are required to be compared against long-term wind-wave records. Historical validation of models used in wave-climate projection studies against historical observations has been variable with no standard wave dataset for verifying wave-climate simulations established within the community. Fig. 8 shows that historical GCM-forced representations of wave climate have been verified (or not) against a range of historical wave-climate datasets which differ in their climatologies. Each research modelling group have used different observation datasets each have their own characteristics which affect the representation of extremes and/or model parameterisations (e.g. assimilated data sources, time-spans, spatio-temporal resolutions and methods of interpolation amongst others). Therefore, the community 'ensemble' contains projection datasets of varying skill.

Fig. 8 shows that the ERA-Interim and ERA-40 global reanalysis along with in-situ observational data sets have been the most used within the community to verify the historical/present global wave climate. Regionally, most studies have either used in-situ observations (usually taken from Waverider buoys). Notably, $10 \%$ of regional studies and $25 \%$ of global studies have not reported any verification at all which raises questions regarding model uncertainty, deficiencies and the processes responsible for these. Whilst no specific validation dataset is preferred, establishing the variance amongst available datasets (including newly released datasets such as ERA5 (ECMWF, 2017) and GOW2.0 (Perez et al., 2017) and the variance amongst them (in representing wave climate variability and its drivers) is needed to improve our understanding of both historical wave-climate change and the quality of GCM-forced wave simulations. 


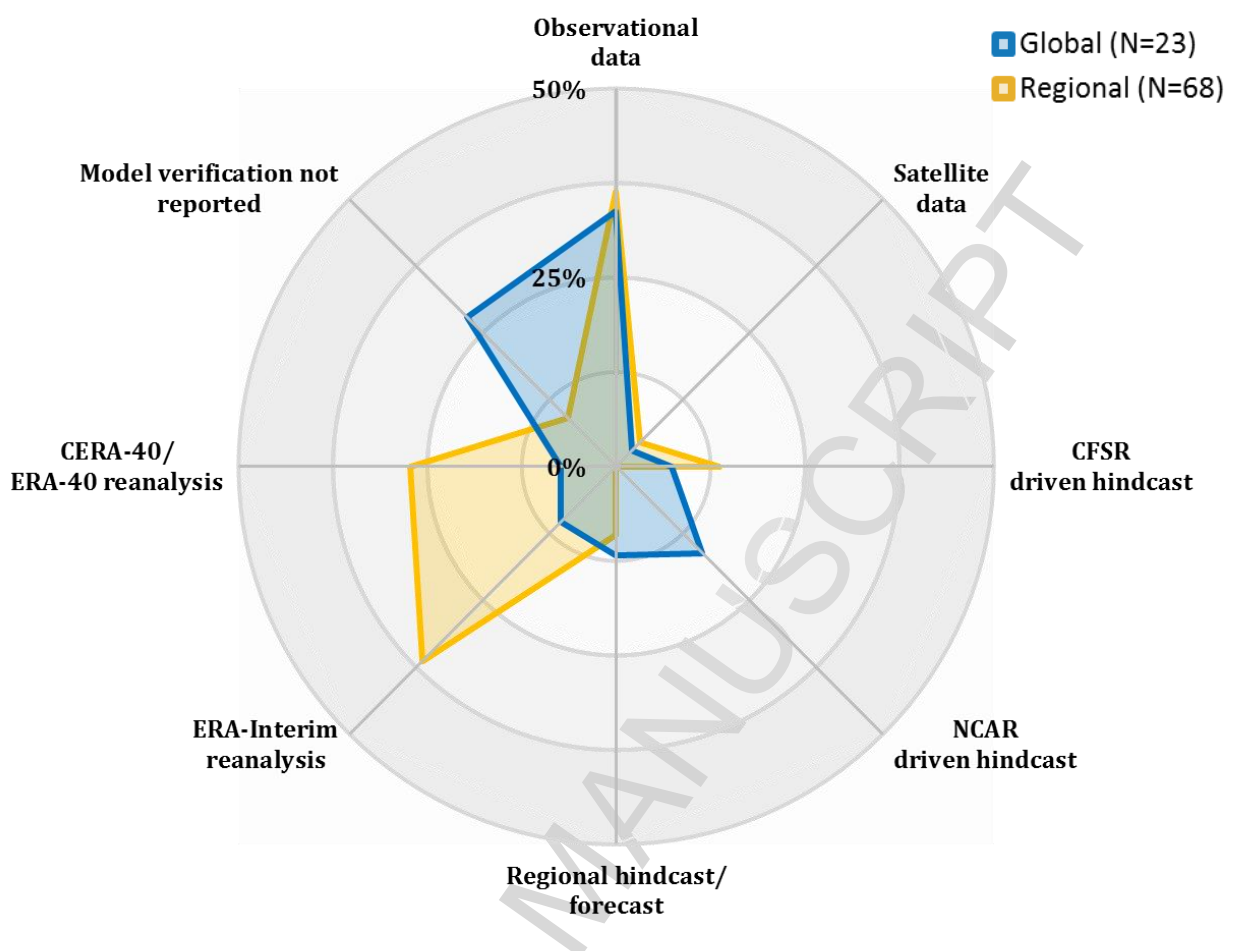

Fig. 8. Wave datasets used by the research community to describe and verify historical wave-climate climate at the global and regional scales. The blue colour code corresponds to global-scale projections and dark yellow code to regional-scale projections as in Fig. 5. The different sources of data have been grouped by type as: observational data (measured either by Waverider buoys, acoustic doppler velocimeter, acoustic doppler current profiler and/or platform stations); satellite data (altimetry); wave hindcasts driven by the NCEP CFSR global wind reanalysis; wave hindcasts driven by the NCEP NCAR global wind reanalysis; regional hindcasts and operational forecasts; ERA-Interim and ERA-40/CERA-40 reanalysis. Studies where verification of GCM-forced wave simulations was not reported or undertaken have been grouped under 'Model verification not reported'. The region acronyms have been geographically defined in Fig. 3.

\subsubsection{Verification approaches}

A range of methodologies have been used to verify GCM-forced wave simulations with no standardized methodology defined in the community. To date, most verification approaches have been deficient with most studies solely focusing on the performance of climate-forced wave simulations to reproduce annual and/or seasonal $\bar{H}_{\mathrm{s}}$. Little to no regard has been given to the skill of climate-forced wave simulations in reproducing temporal variability and/or other wave parameters such period/direction and their extremes (see Supplementary Table S2). Understanding the reliability of GCM-forced wave simulations to represent extremes is essential as the effects of climatological variability of wind-waves are likely to be 
experienced in response to extreme events. In addition, most studies typically present only a limited set of model skill metrics (usually basic bias measures) as an indicator of models' performance, leaving many unanswered questions about the skill of the different aspects of the simulation such as variability. This, combined with the limited spatial-temporal availability of observational data, magnifies the issues regarding projection uncertainty and makes it more challenging to identify the underlying reasons for discrepancies between simulations and observations. The suitability of GCM-forced wave simulations for a specific region, or wave variable, is dependent on the performance metric chosen (Hemer and Trenham, 2016). A standardized range of statistical and cross-validation techniques would help improve confidence (Arlot and Celisse, 2010) and provide a basis to exclude unreasonable models.

\section{Addressing uncertainty using available experiments}

The lack of a standardized methodology amongst the wave-climate projection studies has systematically limited the sample space that can be used to compare experiments to quantify the sources of uncertainty within available datasets (Fig. 6 and 7). Multi-study datasets strictly described as ensembles of opportunity encompass different sources of uncertainty and have limited applicability for extracting policy-relevant data and quantifying these uncertainties (Hemer et al., 2013b). Rather than completing extra simulations at prohibitive computational expense, we have identified multiple sets of experiments within the existing community ensemble of projections where subsets of the uncertainty could be fully or at least partly resolved (Table 1).

Table 1. Sources of uncertainty that can be potentially resolved by combining sets of coordinated experiments within the community ensemble. The different sources of uncertainty have been defined in the Supplementary Information and schematized in Supplementary Information. The numbers represent the number of datasets that could be combined to address each subset of the uncertainty space.

\begin{tabular}{|c|c|c|c|c|c|c|c|c|}
\hline \multirow[b]{2}{*}{$\begin{array}{l}\text { Regio } \\
n\end{array}$} & \multirow[b]{2}{*}{$\begin{array}{l}\text { Inter- } \\
\text { scenari } \\
\text { o }\end{array}$} & \multirow[b]{2}{*}{$\begin{array}{cc}\text { Inter- } & \text { Intra- } \\
\text { mode } & \text { mode } \\
1 & l\end{array}$} & \multicolumn{2}{|c|}{$\begin{array}{c}\text { Atmospheric } \\
\text { downscaling } \\
\text { uncertainty }\end{array}$} & \multicolumn{4}{|c|}{$\begin{array}{c}\text { Wind-wave modelling } \\
\text { uncertainty }\end{array}$} \\
\hline & & & $\begin{array}{c}\text { GCM vs } \\
\text { AGCM/RC } \\
M\end{array}$ & $\begin{array}{c}\text { AGCM/RC } \\
\text { M vs } \\
\text { AGCM/RC } \\
M\end{array}$ & $\begin{array}{l}\text { Sourc } \\
\text { e } \\
\text { terms }\end{array}$ & $\begin{array}{l}\text { Wave } \\
\text { model } \\
\text { s }\end{array}$ & $\begin{array}{c}\text { Statistica } \\
\text { l } \\
\text { approac } \\
\text { h }\end{array}$ & $\begin{array}{c}\text { Dynamica } \\
\text { l vs } \\
\text { Statistical }\end{array}$ \\
\hline Global & $\checkmark(2-4)$ & $\checkmark(2)$ & $\checkmark(2)$ & $\checkmark(2-3)$ & $\begin{array}{l}\checkmark+ \\
(4)\end{array}$ & $\begin{array}{l}\sqrt{ }(2- \\
4)\end{array}$ & $\checkmark(3)$ & $\checkmark(4)$ \\
\hline MS & & & $\checkmark(2)$ & O & & & & $\checkmark(3)$ \\
\hline BS & & $\checkmark(2)$ & O & $\checkmark(2)$ & & & & $\checkmark(2)$ \\
\hline NS & $\checkmark+(3)$ & $\checkmark(2)$ & $\checkmark(2)$ & o & $\begin{array}{l}\sqrt{ }+ \\
(2)\end{array}$ & & & $\checkmark(3)$ \\
\hline AO & & & & & & & & $\checkmark(2)$ \\
\hline ENA & & $\checkmark(2)$ & $\checkmark(3)$ & $\checkmark+(3)$ & $\begin{array}{l}\checkmark+ \\
(2)\end{array}$ & $\sqrt{ }+(2)$ & & $\checkmark(5)$ \\
\hline WNA & & & & & & & & $\checkmark(3)$ \\
\hline ENP & $\checkmark(2)$ & $\checkmark(2)$ & & & & & & \\
\hline WNP & $\checkmark(2)$ & & & & & & & \\
\hline
\end{tabular}

$\checkmark$ - uncertainty that can be fully isolated to resolve 
$\checkmark+$ - uncertainty that can be potentially isolated to resolve after $\checkmark$

o - uncertainty that can be potentially resolved with EURO-CORDEX data

Given the current context of wave-climate projections, one approach to limit the experimental sample space within the community ensemble of projections is to cluster forcing models together on the basis of their representation of SST distribution and projected change (see methods section 3.3 and Fig. 9). Under the assumption that clustered GCM models act similarly, the forcing scenario uncertainty can be disregarded. On this basis, there is opportunity to potentially resolve the cascade of uncertainty (excluding intra-model variability) inherent in projecting future wave-climate change. At the regional scale, the North Atlantic and North Sea are regions where multiple sources of variance can be isolated/resolved (Table 1). However, the number of overlapping experiments, in some cases, might be too limited to systematically sample the full range of variance from a specific uncertainty source. In comparison, the other regions are notably limited in the number of uncertainty sources that could be quantified. In these cases, significant benefit could be alternatively obtained by combining a greater number of datasets to systematically resolve the variance associated with study methodologies (Hemer et al., 2013a). 
a)

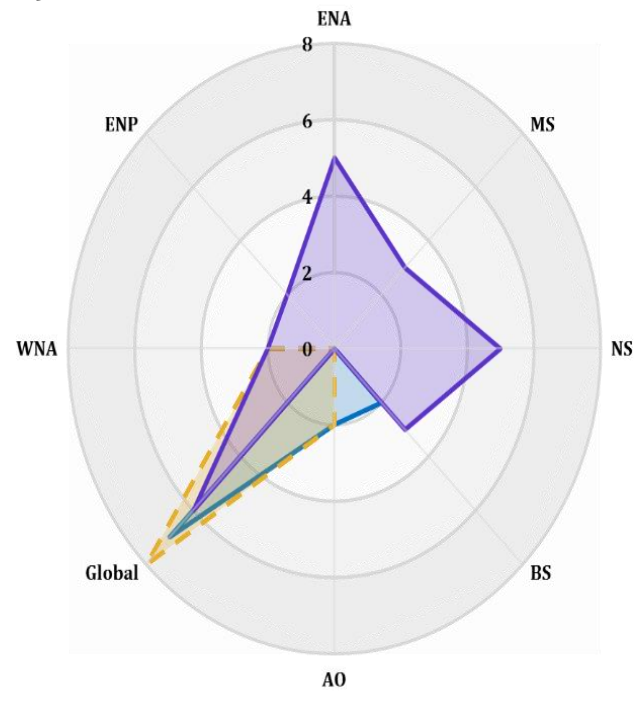

b)

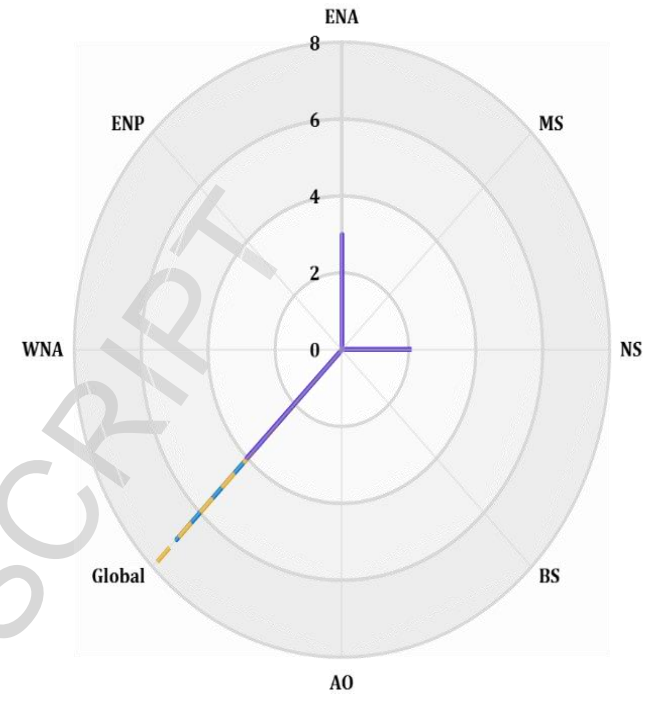

c)

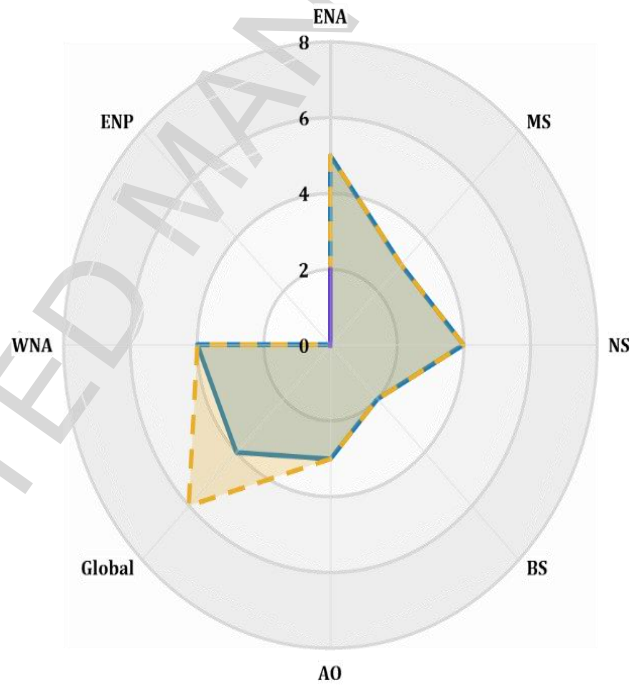

Fig. 9. The number of datasets available in each oceanic region grouped by SST cluster and forcing climate scenario (SRESA1B - purple, RCP8.5 - yellow, RCP4.5 - blue). a) Cluster 2. b) Cluster 3. c) Cluster ECEARTH. The definition of each cluster is provided in the methods. Clusters 0 and 1 are not shown as the sample overlap between datasets only occurs at the global scale (ranging between 2 and 6 datasets).

Process-oriented wave climate projection experiments, in the context of those described in the CMIP5 (Taylor et al., 2012) and CORDEX (Giorgi and Jr., 2015; Gutowski Jr et al., 2016) strategies, will be required to resolve uncertainties that cannot be sufficiently resolved and to more adequately explore the full range of uncertainty in GCM-forced wave simulations (and expose irreducible uncertainties). The CORDEX coordinated sets of CMIP5 regional downscaled projections can be used as a basis to resolve the uncertainty introduced by the downscaling step into climate-forced wave simulations across several 
regions of the global ocean. This would help establish the benefits of using high-resolution GCMs when projecting the climate change signal in these regions relative to direct forcing of spectral wave models with AOGCM outputs.

\section{Conclusions}

The present study synthesises and reconciles multiples lines of evidence in the literature on projected changes in wind-wave climate in response to global warming by analysing the level consensus between 91 published wind-wave climate projection studies. We show that despite large inconsistencies in the study methodologies employed amongst existing wave-climate projection studies, there is strong consensus in the projected signal of change in both the mean and extreme ocean wind-wave height over the end of this century across 15 and 5 of 21 regions of the oceans, respectively. Whilst the evidence base available in the literature provides considerable confidence in the sign of projected change in $\bar{H}_{\mathrm{s}}$ in these regions, it should be viewed in the context of the relatively narrow sampling of the uncertainty space seen in the community ensemble of wind-wave climate projections. Notably, we find that published projections of future changes in the full wave field (including wave period and direction) are limited, despite being pre-requisite knowledge for coastal management/climate-adaption assessments as sugges ted by the IPCC. Also, we show that regional wind-wave climate projections have been applied to Europe, thus leaving the regions of the world at greater risk and with lower adaptive capacity largely overlooked.

In the last decade, much effort has gone into investigating possible scenarios of future wave-climate change. Whilst a specifically designed experiment would best resolve the sources of uncertainty introduced during the process of wave climate projections, added value can be extracted from the existing studies. We have identified multiple sets of inter-comparison experiments, using pre-existing studies, where these uncertainties could potentially be isolated (or limited), to improve understanding of which other sources of uncertainty dominate, and which are relatively insignificant. Our approach need not be limited to wave-climate research and could be applied to other research communities (hydrological, stream flow, storm surge and sea-level rise, Little et al., 2015), where future changes driven by global warming are derived through a similar multi-step projection modelling process and uncertainty is likewise poorly understood.

Climate-driven variability of the wave climate, together with storm-surges and seasonal water level anomalies, has been shown to have broad-scale implications for coastal vulnerability (Little et al., 2015). The development of adaptation and mitigation strategies to respond to the potential impacts of climateinduced changes to the coastal- and open-ocean environments is hence heavily reliant on high levels of confidence in wave-climate projections (height, length and directions). Whilst various sources of uncertainty are yet to be adequately quantified, we take confidence from the level of consensus amongst studies on the sign of projected change over most of the oceans. Increased certainty in wave climate projections can only benefit coastal stakeholders as we look towards the development of improved regional coastal sea-level information from the climate community (Stammer et al., 2018).

\section{Acknowledgements}


The study was conceived to aid the wave-climate community and the COWCLIP project, an international collaborative working group endorsed by the World Climate Research Program and the Joint Commission on Oceanography and Marine Meteorology of the World Meteorological Organization and the UNESCO Intergovernmental Oceanographic Commission. We acknowledge Nobuhito Mori (Kyoto University, Japan) and Alvaro Semedo (UNESCO-IHE, The Netherlands) for helpful comments and discussions on earlier versions of the manuscript. We thank all contributors to the COWCLIP project including Johan Aarnes, Øyvind Breivik (Norwegian Meteorological Institute, Norway) and Justin Stopa (The French Research Institute for Exploitation of the Sea, France). JM is supported through funding from CSIIRO and Griffith University. MH is supported through funding from the Earth Systems and Climate Change Hub of the Australian Government's National Environmental Science Programme. DS is supported through funding by the Queensland Government's Advance Queensland Research Fellowship and the City of Gold Coast, Australia.

\section{Author contributions}

All authors jointly conceived the study and contributed with scientific knowledge.

J.M. analysed data and prepared the manuscript, with all authors discussing results and implications and commenting on the manuscript at all stages.

\section{Competing financial interests}

The authors declare no competing financial interests. 


\section{References}

Aarnes, O.J., M. Reistad, Ø. Breivik, E. Bitner-Gregers en, L. Ingolf Eide, O. Gramstad, A. K. Magnusson, B. Natvig, and E. Vanem, 2017. Projected changes in significant wave height toward the end of the 21st century: Northeast Atlantic. J. Geophys. Res. Oceans, 122.

Albert, S., Leon, J.X., Grinham, A.R., Church, J.A., Gibbes, B.R. and Woodroffe, C.D., 2016. Interactions between sea-level rise and wave exposure on reef island dynamics in the Solomon Islands. Environmental Research Letters, 11(5): 054011.

Alves, J.-H.G.M., 2006. Numerical modeling of ocean swell contributions to the global wind-wave climate. Ocean Modelling, 11(1-2): 98-122.

Arblaster, J.M., Meehl, G.A. and Karoly, D.J., 2011. Future climate change in the Southern Hemisphere: Competing effects of ozone and greenhouse gases. Geophysical Research Letters, 38(2): n/a-n/a.

Arlot, S. and Celisse, A., 2010. A survey of cross -validation procedures for model selection. Statist. Surv., 4: 40-79.

Bennett, W., Karunarathna, H., Mori, N. and Reeve, D., 2016. Climate Change Impacts on Future Wave Climate around the UK. Journal of Marine Science and Engineering, 4(4): 78.

Casas-Prat, M., Wang, X.L. and Swart, N., 2018. CMIP5-based global wave climate projections including the entire Arctic Ocean. Ocean Modelling.

Church, J. A. et al. in IPCC Climate Change 2013: The Physical Science Basis (eds Stocker, T. F. et al.) 11371216 (Cambridge Univ. Press, 2014).

Coelho, C., Silva, R., Veloso-Gomes, F. and Taveira-Pinto, F., 2009. Potential effects of climate change on northwest Portuguese coastal zones. ICES Journal of Marine Science, 66(7): 1497-1507.

Giorgi, F. and Jr., W.J.G., 2015. Regional Dynamical Downscaling and the CORDEX Initiative. Annual Review of Environment and Resources, 40(1): 467-490.

Goodwin, I.D., Freeman, R. and Blackmore, K., 2013. An insight into headland sand bypassing and wave climate variability from shoreface bathymetric change at Byron Bay, New South Wales, Australia. Marine Geology, 341: 29-45.

Gutowski Jr, W.J., Giorgi, F., Timbal, B., Frigon, A., Jacob, D., Kang, H.-S., Raghavan, K., Lee, B., Lennard, C., Nikulin, G., amp, apos, Rourke, E., Rixen, M., Solman, S., Stephenson, T. and Tangang, F., 2016. WCRP COordinated Regional Downscaling EXperiment (CORDEX): a diagnostic MIP for CMIP6. Geoscientific Model Development, 9(11): 4087-4095.

Field, C.B.; et al. in IPCC Climate Change 2014: Impacts, Adaptation, and Vulnerability. Part A: Global and Sectoral Aspects. (Cambridge University Press, 2016).

Flato, G., Marotzke, J., Abiodun, B., Braconnot, P., Chou, S. C., Collins, W., Cox, P., Driouech, F., Emori, S., Eyring, V., Forest, C., Gleckler, P., Guilyardi, E., Jakob, C., Kattsov, V., Reason, C. \& Rumm ukain en, M. 2013. Evaluation of climate models. In: STOCKER, T. F., QIN, D., PLATTNER, G. K., TIGNOR, M., ALLEN, S. K., DOSCHUNG, J., NAUELS, A., XIA, Y., BEX, V. \& MIDGLEY, P. M. (eds.) Climate Change 2013: The Physical Science Basis. Contribution of Working Group I to the Fifth Assessment Report of the Intergovernmental Panel on Climate Change. Cambridge, UK: Cambridge University Press.

Harley, M.D., Turner, I.L., Kinsela, M.A., Middleton, J.H., Mumford, P.J., Splinter, K.D., Phillips, M.S., Simmons, J.A., Hanslow, D.J. and Short, A.D., 2017. Extreme coastal erosion enhanced by anomalous extratropical storm wave direction. Scientific Reports, 7(1): 6033.

Hemer, M. and Wang, X.L., 2017. The Coordinated Ocean Wave Climate Project: Achievements to date and outstanding challenges, 1st International Works hop on Waves, Storm Surges and Coastal Hazards, Liverpool, United Kingdom.

Hemer, M.A., Fan, Y., Mori, N., Semedo, A. and Wang, X.L., 2013a. Projected changes in wave climate from a multi-model ensemble. Nature Climate Change, 3(5): 471-476.

Hemer, M.A., McInnes, K.L. and Ranasinghe, R., 2013b. Projections of climate change-driven variations in the offshore wave climate off south eastern Australia. International Journal of Climatology, 33(7): 1615-1632.

Hemer, M.A. and Trenham, C.E., 2016. Evaluation of a CMIP5 derived dynamical global wind wave climate model ensemble. Ocean Modelling, 103: 190-203. 
Hemer, M.A., Wang, X.L., Church, J.A. and Swail, V.R., 2010. MODELING PROPOSAL: Coordinating Global Ocean Wave Climate Projections. Bulletin of the American M eteor ological Society, 91(4): 451-454.

Hemer, M.A., Wang, X.L., Weisse, R. and Swail, V.R., 2012. Advancing Wind-Waves Climate Science. Bulletin of the American Meteorological Society, 93(6): 791-796.

Hoeke, R.K., McInnes, K.L., Kruger, J.C., McNaught, R.J., Hunter, J.R. and Smithers, S.G., 2013. Widespread inundation of Pacific islands triggered by distant-source wind-waves. Global and Planetary Change, 108: 128-138.

Khon, V.C., I. I. Mokhov, F. A. Pogarskiy, A. Babanin, K. Dethloff, A. Rinke, and H. Matthes, 2014. Wave heights in the 21st century Arctic Ocean simulated with a regional climate model. Geophysical Research Letters(41): 2956-2961.

Little, C.M., Horton, R.M., Kopp, R.E., Oppenheimer, M. and Yip, S., 2015. Uncertainty in Twenty-FirstCentury CMIP5 Sea Level Projections. Journal of Climate, 28(2): 838-852.

Ma, J., Foltz, G.R., Soden, B.J., Huang, G., He, J. and Dong, C., 2016. Will surface winds weaken in response to global warming? Environmental Research Letters, 11(12): 124012.

Mastrandrea, M.D., C.B. Field, T.F. Stocker, O. Edenhofer, K.L. Ebi, D.J., Frame, H.H., E. Kriegler, K.J. Mach, P.R. Matschoss, G.-K. Plattner, G.W. Yohe and and F.W. Zwiers, 2010. Guidance Note for Lead Authors of the IPCC Fifth Assessment Report on Consistent Treatment of Uncertainties, Intergovernmental Panel on Climate Change (IPCC), CA, USA.

Mastrandrea, M.D., Mach, K.J., Plattner, G.-K., Edenhofer, O., Stocker, T.F., Field, C.B., Ebi, K.L. and Matschoss, P.R., 2011. The IPCC AR5 guidance note on consistent treatment of uncertainties: a common approach across the working groups. Climatic Change, 108(4): 675.

McInnes, K.L., Erwin, T.A. and Bathols, J.M., 2011. Global Climate Model projected changes in $10 \mathrm{~m}$ wind speed and direction due to anthropogenic climate change. Atmospheric Science Letters, 12(4): 325-333.

Mizuta, R., Arakawa, O., Ose, T., Kusunoki, S., Endo, H. and Kitoh, A., 2014. Classification of CMIP5 Future Climate Responses by the Tropical Sea Surface Temperature Changes. Sola, 10(0): 167-171.

Morim, J., Cartwright, N., Etemad-Shahidi, A., Strauss, D. and Hemer, M., 2016. Wave energy resource assessment along the Southeast coast of Australia on the basis of a 31-year hindcast. Applied Energy, 184: 276-297.

Murakami, H., Mizuta, R. and Shindo, E., 2011. Future changes in tropical cyclone activity projected by multi-physics and multi-SST ensemble experiments using the 60-km-mesh MRI-AGCM. Climate Dynamics, 39(9-10): 2569-2584.

Murakami, H., Sugi, M. and Kitoh, A., 2012. Future changes in tropical cyclone activity in the North Indian Ocean projected by high-resolution MRI-AGCMs. Climate Dynamics, 40(7-8): 1949-1968.

Neumann, B., Vafeidis, A.T., Zimmermann, J. and Nicholls, R.J., 2015. Future Coastal Population Growth and Exposure to Sea-Level Rise and Coastal Flooding - A Global Assessment. PLOS ONE, 10(3): $\mathrm{e} 0118571$.

Nicholls, R. J. et al. in IPCC Climate Change 2007: Impacts, Adaptation and Vulnerability (eds Parry, M. L., Canziani, O. F., Palutikof, J. P., van der Linden, P. J. \& Hanson, C. E.) 315-356 (Cambridge Univ. Press, 2007).

Perez, J., Menendez, M. and Losada, I.J., 2017. GOW2: A global wave hindcast for coastal applications. Coastal Engineering, 124: 1-11.

Ranasinghe, R., 2016. Assessing climate change impacts on open sandy coasts: A review. Earth-Science Reviews, 160: 320-332.

Ruggiero, P., Buijsman, M., Kaminsky, G.M. and Gelfenbaum, G., 2010. Modeling the effects of wave climate and sediment supply variability on large-scale shoreline change. Marine Geology, 273(1-4): 127140.

Shimura, T., Mori, N. and Mase, H., 2015a. Future Projection of Ocean Wave Climate: Analysis of SST Impacts on Wave Climate Changes in the Western North Pacific. Journal of Climate, 28(8): 3171 3190.

Shimura, T., Mori, N. and Mase, H., 2015b. Future Projections of Extreme Ocean Wave Climates and the Relation to Tropical Cyclones: Ensemble Experiments of MRI-AGCM3.2H*. Journal of Climate, 28(24): 9838-9856.

Sierra, J.P. and Casas-Prat, M., 2014. Analysis of potential impacts on coastal areas due to changes in wave conditions. Climatic Change, 124(4): 861-876. 
Sigmond, M., Reader, M.C., Fyfe, J.C. and Gillett, N.P., 2011. Drivers of past and future Southern Ocean change: Stratospheric ozone versus greenhouse gas impacts. Geophysical Research Letters, 38(12): n/a-n/a.

Stammer, D., R. van de Wal, and R. J. Nicholls, 2018. Sea level 2017 conference looks to coastal sea level rise impact, Eos, 99, https://doi.org/10.1029/2018E0 090093.

Stanton, B., Dessai, S. and Paavola, J., 2016. A systematic review of the impacts of climate variability and change on electricity systems in Europe. Energy, 109: 1148-1159.

Taylor, K.E., Stouffer, R.J. and Meehl, G.A., 2012. An Overview of CMIP5 and the Experiment Design. Bulletin of the American Meteorological Society, 93(4): 485-498.

Young, I., Zieger, S. and Babanin, A., 2011. Global Trends in Wind Speed and Wave Height. Science, 332(6028): 451-455. 

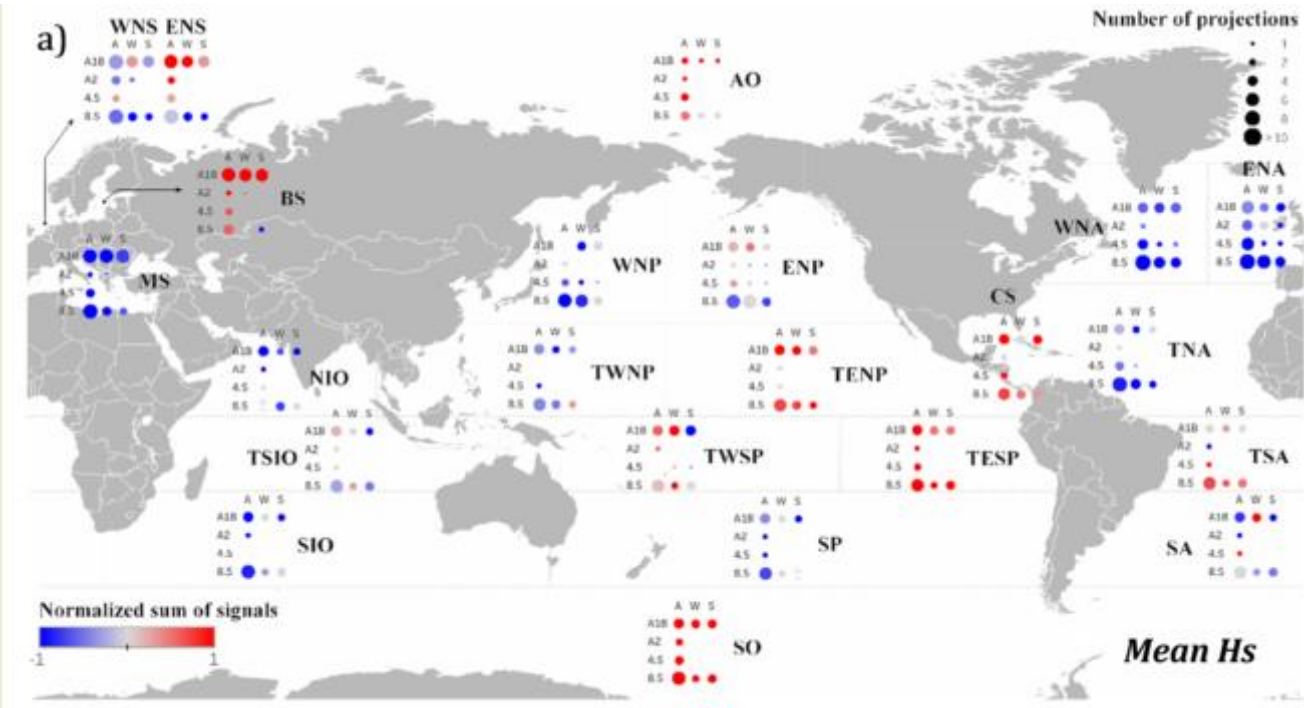

Mean Hs

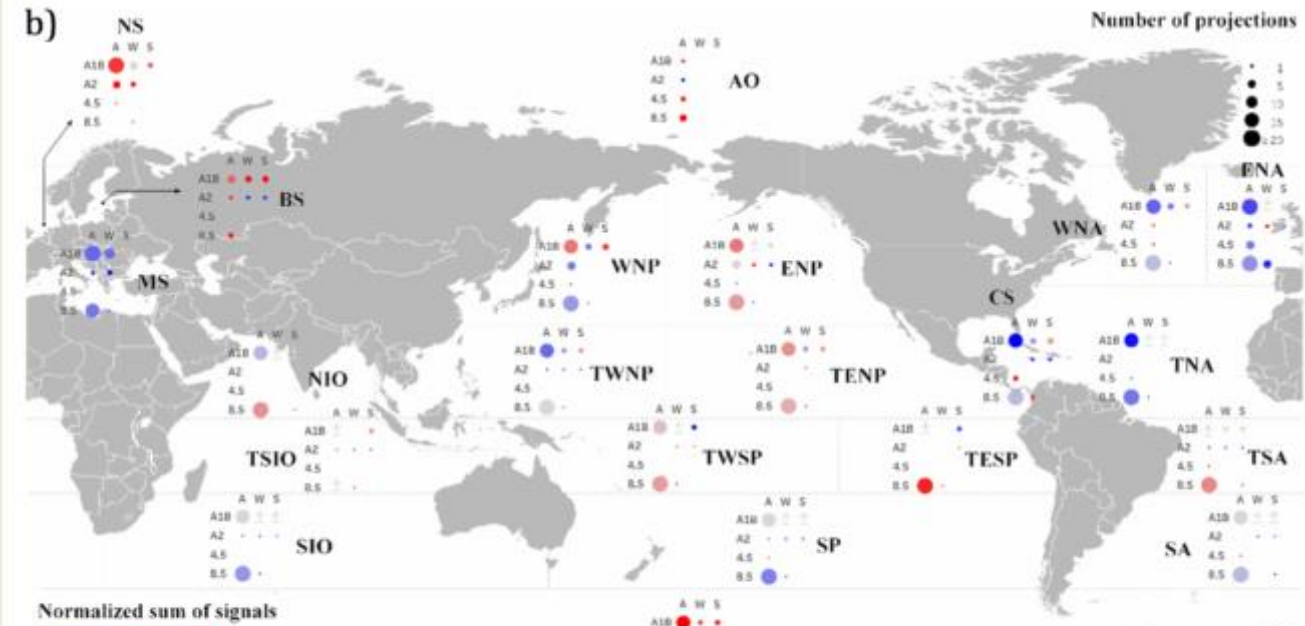

Normalized sum of signals
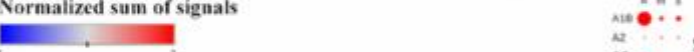

Extreme Hs

Graphical Abstract 


\section{Highlights}

- Consensus-based analysis of91 published wind-wave climate projection assessments

- Regions at high risk and with lower adaptive capacity have been largely overlooked

- Projection uncertainty surrounding wave climate projections has been poorly sampled

- Current knowledge on future wind-climate changes is limited to significant wave height

- Added value can be extracted from existing studies to resolve uncertainty sources 


\section{Accepted Manuscript}

On the concordance of 21 st century wind-wave climate projections

Joao Morim, Mark Hemer, Nick Cartwright, Darrell Strauss, Fernando Andutta

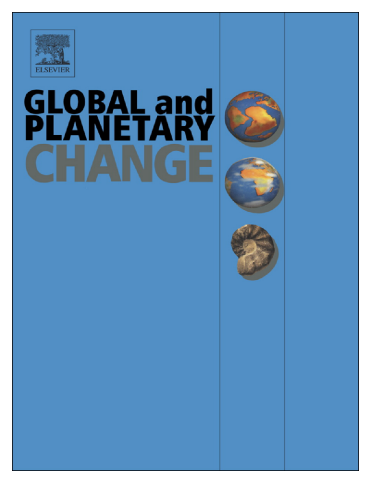

PII:

S0921-8181(18)30107-3

DOI: doi:10.1016/j.gloplacha.2018.05.005

Reference: GLOBAL 2773

To appear in: Global and Planetary Change

Received date: 15 February 2018

Revised date: 10 May 2018

Accepted date: 14 May 2018

Please cite this article as: Joao Morim, Mark Hemer, Nick Cartwright, Darrell Strauss, Fernando Andutta, On the concordance of 21st century wind-wave climate projections. Global and Planetary Change(2017), doi:10.1016/j.gloplacha.2018.05.005

This is a PDF file of an unedited manuscript that has been accepted for publication. As a service to our customers we are providing this early version of the manuscript. The manuscript will undergo copyediting, typesetting, and review of the resulting proof before it is published in its final form. Please note that during the production process errors may be discovered which could affect the content, and all legal disclaimers that apply to the journal pertain. 